\title{
Determinants of leptomeningeal collateral flow in stroke patients with a middle cerebral artery occlusion
}

\author{
Tom van Seeters ${ }^{1}$ - Geert Jan Biessels ${ }^{2}$ - L. Jaap Kappelle ${ }^{2}$ - Yolanda van der Graaf ${ }^{3}$. \\ Birgitta K. Velthuis ${ }^{1} \cdot$ on behalf of the Dutch acute stroke study (DUST) investigators
}

Received: 3 May 2016 / Accepted: 7 July 2016 / Published online: 20 July 2016

(C) The Author(s) 2016. This article is published with open access at Springerlink.com

\begin{abstract}
Introduction Poor leptomeningeal collateral flow is related to worse clinical outcome in acute ischemic stroke, but the factors that determine leptomeningeal collateral patency are largely unknown. We explored the determinants of leptomeningeal collateral flow and assessed their effect on the relation between leptomeningeal collateral flow and clinical outcome.

Methods We included 484 patients from the Dutch acute stroke study (DUST) with a middle cerebral artery (MCA) occlusion. The determinants of poor leptomeningeal collateral flow ( $\leq 50 \%$ collateral filling) were identified with logistic regression. We calculated the relative risk (RR) of poor leptomeningeal collateral flow in relation to poor clinical outcome (90-day modified Rankin Scale 3-6) using Poisson regression and assessed whether the determinants of leptomeningeal collateral flow affected this relation.

Results Leptomeningeal collateral flow was poor in 142 patients $(29 \%)$. In multivariable analyses, higher admission glucose level (odds ratio (OR) $1.1 \mathrm{per} \mathrm{mmol} / \mathrm{L}$ increase $(95 \% \mathrm{CI}$ 1.0-1.2)), a proximal MCA occlusion (OR 1.9 (95 \% CI 1.3$3.0)$ ), and an incomplete posterior circle of Willis (OR 1.7 (95\% CI 1.1-2.6)) were independently related to poor leptomeningeal collateral flow. Poor leptomeningeal collateral
\end{abstract}

Tom van Seeters

T.vanSeeters@umcutrecht.nl

1 Department of Radiology, University Medical Center Utrecht, Heidelberglaan 100, HP E01 132, 3584 CX Utrecht, The Netherlands

2 Department of Neurology, Brain Center Rudolf Magnus, University Medical Center Utrecht, Utrecht, The Netherlands

3 Julius Center for Health Sciences and Primary Care, University Medical Center Utrecht, Utrecht, The Netherlands flow was related to poor clinical outcome (unadjusted RR 1.7 (95\% CI 1.4-2.0)), and this relation was not affected by the determinants of leptomeningeal collateral flow.

Conclusion Our study shows that admission glucose level, a proximal MCA occlusion, and an incomplete ipsilateral posterior circle of Willis are determinants of leptomeningeal collateral flow that represent a combination of congenital, acquired, and acute factors. After adjustment for these determinants, leptomeningeal collateral flow remains related to clinical outcome.

Keywords Leptomeningeal collateral flow $\cdot$ Ischemic stroke · Stroke etiology $\cdot$ Clinical outcome $\cdot$ CT angiography

\section{Introduction}

Leptomeningeal collaterals are a network of small blood vessels connecting distal regions of the intracerebral arterial system $[1,2]$. They can provide an alternative route for blood flow to the brain in case of a disruption of the primary blood flow and may therefore protect brain tissue against irreversible damage in case of acute ischemia. Presence of good leptomeningeal collateral flow has been associated with better functional outcomes and smaller infarct volumes after acute ischemic stroke [3-20]. However, factors that determine variation in leptomeningeal collateral flow between patients are largely unknown. Previous studies suggested genetic factors [21] and the vascular risk profile, such as prior hypertension [12, 22, 23], age [22-24], statin use [24], metabolic syndrome [22], and circle of Willis completeness [2], to be related to the patency of leptomeningeal collaterals, but some findings of these studies are contradictory. The presence of an internal carotid artery stenosis or occlusion might also be related to the amount of leptomeningeal collateral flow. In addition, 
factors that occur at the time of stroke, including higher systolic blood pressure at admission [12], higher blood glucose levels [22], and the location of the occlusion [4], may determine leptomeningeal collateral patency.

In the last decade, CT angiography (CTA) has been successfully incorporated into acute stroke imaging protocols in many stroke centers worldwide and recently has been proven useful to select patients for intra-arterial treatment [25-29]. CTA also offers the possibility to assess the leptomeningeal collateral flow, the circle of Willis, and the extracranial cervical vessels [30]. Leptomeningeal collaterals themselves cannot be visualized directly on CTA, but their patency can be determined by assessing the amount of vascular enhancement in the affected brain area distal of the occluded artery $[4,8]$. This is referred to as leptomeningeal collateral flow.

In the present study, we explored possible determinants of leptomeningeal collateral flow in a large prospective cohort of stroke patients with an occlusion of the middle cerebral artery (MCA). We investigated the relation between leptomeningeal collateral flow and clinical outcome and assessed whether this relation was affected by the determinants of leptomeningeal collateral flow.

\section{Methods}

\section{Study population}

All patients participated in the Dutch acute stroke study (DUST), a prospective observational cohort study in six university and eight non-university hospitals in The Netherlands [19]. A detailed description of the DUST study protocol has been published previously [31]. The DUST study population consists of patients with symptoms of acute ischemic stroke of less than 9-h duration, who were enrolled between May 2009 and August 2013. Patients with another diagnosis on admission non-contrast CT (NCCT) such as intracranial hemorrhage were excluded. All patients underwent NCCT, CTA, and CT perfusion (CTP) on admission. Ethical approval was obtained from the medical ethics committee of the University Medical Center Utrecht and local approval from all participating centers. Informed consent was obtained from patients or their legal representatives. The medical ethics committee waived the need for informed consent for patients who died before informed consent could be obtained.

For the present study, we selected patients with a confirmed occlusion in the M1 or M2 segment of the MCA on admission CTA, as leptomeningeal collaterals are needed most if the main blood supply to the downstream territory is completely interrupted. Patients with an isolated occlusion of the intracranial internal carotid artery without an occlusion of the M1 segment were therefore not included $(n=42)$. Patients were excluded if information about clinical outcome after 90 days was missing (Fig. 1).

\section{Admission CT angiography}

All imaging data were assessed by one of three observers with at least 5 years of experience in neurovascular imaging, blinded for all clinical information except for the side of symptoms. A detailed description of the imaging protocol has been described elsewhere [31]. The CTA was scanned from the aortic arch to cranium vertex, and $50-70 \mathrm{~mL}$ of contrast material was injected followed by $40 \mathrm{~mL}$ of saline with a flow of $6 \mathrm{~mL} / \mathrm{s}$. The scan delay after contrast injection was calculated either from time to peak arterial enhancement on CTP, or by a trigger based on Hounsfield unit threshold measurement in the aortic arch.

\section{Assessment of leptomeningeal collateral flow}

To assess the leptomeningeal collateral circulation, the observers assessed the CTA source images and maximum intensity projections (MIP) using an interactive sliding slab technique, allowing the observers to increase and decrease the MIP slice thickness (Fig. 2). CTA source images and MIP images were assessed for leptomeningeal collateral flow across the entire MCA territory. The patency of the

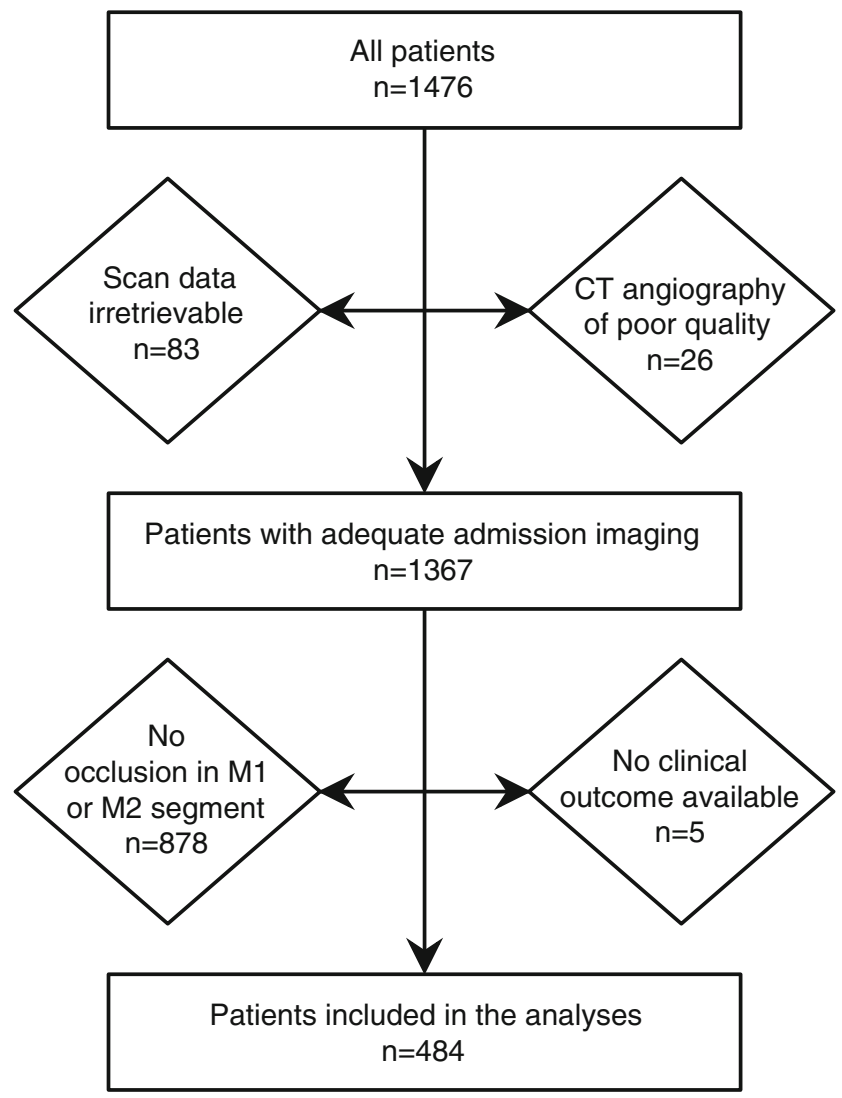

Fig. 1 Flowchart depicting the number of patients included in the study 


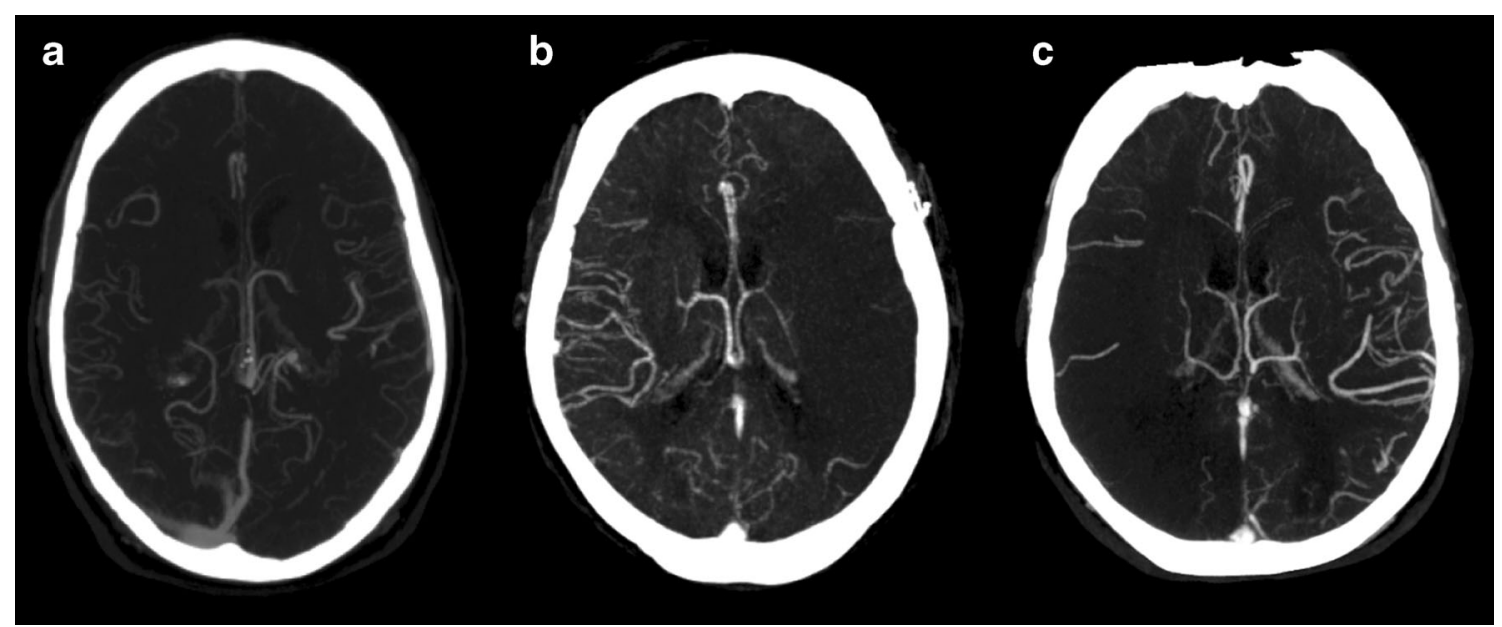

Fig. 2 Examples of patients with good $(A)$ and poor leptomeningeal collateral flow ( $B$ and $C$ ), depicted with 20 -mm-thick maximum intensity projection (MIP) reconstructions. $A$ Good leptomeningeal collateral flow in a patient with a right-sided ischemic stroke. There was no proximal occlusion and the circle of Willis was complete. The 90-day modified Rankin Scale (mRS) score was 1. B Poor leptomeningeal

leptomeningeal collateral circulation was defined as either poor or good $[4,8]$. Poor leptomeningeal collateral status was defined as $\leq 50 \%$ collateral filling of the perfusion territory of the affected MCA or MCA branch territory $[4,8]$.

\section{Possible determinants of leptomeningeal collateral flow}

\section{Patient characteristics}

The selection of patient characteristics that were considered potential determinants of leptomeningeal collateral flow was based on previous literature. These determinants included age, prior hypertension, prior diabetes, and systolic blood pressure and glucose level at admission [12, 22-24].

\section{Circle of Willis patency}

Circle of Willis completeness was assessed on admission CTA. The anterior circle of Willis pathway was considered incomplete if the anterior communicating artery was not visible or if the A1 segment of one of the anterior cerebral arteries was hypoplastic $(<1.0 \mathrm{~mm})$, absent, or both. Posterior circle of Willis collaterals were considered incomplete if the posterior communicating artery or P1 segment of the posterior cerebral artery was hypoplastic $(<1.0 \mathrm{~mm})$ or absent ipsilateral to the side of the perfusion deficit.

\section{Location of the occlusion}

The location of the occlusion was also assessed on admission CTA and was classified according the most proximal part of the occlusion, either in the intracranial internal carotid artery, collateral flow in a patient with a left-sided ischemic stroke and a proximal occlusion in the M1 segment. The 90-day mRS was 6. $C$ Poor leptomeningeal collateral flow in a patient with a right-sided ischemic stroke and an ipsilateral incomplete posterior circle of Willis. The 90day $\mathrm{mRS}$ was also 6

M1 segment, or M2 segment. A proximal MCA occlusion was defined as an occlusion of the M1 segment (with or without an occlusion of the intracranial internal carotid artery).

\section{Ipsilateral extracranial internal carotid artery stenosis or occlusion}

The ipsilateral extracranial internal carotid artery was assessed on CTA. A stenosis was measured according to the North American Symptomatic Carotid Endarterectomy Trial (NASCET) criteria and was considered significant if it was $>70 \%$ [32].

\section{Clinical outcome}

The clinical outcome was assessed after 90 days with the modified Rankin Scale (mRS) [33]. Poor clinical outcome was defined as a score of 3-6, whereas good clinical outcome was defined as a score of $0-2$. The mRS was collected by a trained research nurse or neurologist by telephone interview [34].

\section{Analyses}

Single imputation was performed to account for missing data. Continuous variables were truncated at the first and 99th percentile to minimize the effect of outliers [35]. First, we used logistic regression to investigate whether patient characteristics, presence of a proximal MCA occlusion, circle of Willis completeness, or presence of an extracranial $>70 \%$ internal carotid artery stenosis or occlusion were related to poor leptomeningeal collateral flow. Multivariable analyses were 
performed including the significant $(p<0.05)$ variables from the univariable analyses. We did not include stroke severity and the extent of the ischemic area on NCCT and CTA in these analyses, as these are the consequence of poor leptomeningeal collateral flow instead of potential determinants. We also did not adjust for treatment because this cannot be a determinant of leptomeningeal collateral flow, since this treatment is administered after the CTA has been made.

Next, we calculated the relative risk (RR) for the relation between leptomeningeal collateral flow and clinical outcome using Poisson regression [36]. We investigated whether this relation was affected by the factors that were associated with leptomeningeal collateral flow, by evaluating the change of the RR in multivariable analyses after adjusting for these factors. We also assessed possible interaction effects between these factors and patency of leptomeningeal collateral flow in relation to clinical outcome. As stroke severity and treatment can be confounding factors for the relation between leptomeningeal collateral flow and clinical outcome, we included them in the Poisson regressions. All analyses were performed with $\mathrm{R}$ version 3.0.2.

\section{Results}

A total of 489 patients had an occlusion of an M1 or M2 segment on admission CTA (Fig. 1). After exclusion of 5 patients $(1.0 \%)$ with missing information on clinical outcome, 484 patients remained for the analyses. The mean age was 66.6 \pm 14.6 years, $268(55 \%)$ patients were male, and the median admission NIHSS was 13 (interquartile range 8-17). The most proximal part of the occlusion was located in the M1 segment in 234 patients ( $48 \%$ ) and in the M2 segment in 183 patients (38\%). In the remaining 67 patients $(14 \%)$, there was an occlusion of the intracranial internal carotid artery in combination with an occlusion of the M1 segment. Leptomeningeal collateral flow was poor in 142 patients (29\%) and good in 342 patients ( $71 \%)$. At 90 days, 251 patients $(52 \%)$ had a poor clinical outcome. Additional patient characteristics can be found in Table 1.

\section{Determinants of leptomeningeal collateral flow}

Univariable logistic regression analyses showed that higher admission glucose levels, presence of a proximal intracranial occlusion, and an incomplete ipsilateral posterior circle of Willis were related to poor leptomeningeal collateral flow (Table 2). Age, systolic blood pressure at admission, prior hypertension, prior diabetes, and presence of a significant internal carotid artery stenosis or occlusion were not related to poor leptomeningeal collateral flow.

All variables that were determinants of poor leptomeningeal collateral flow in univariable analyses were also related to poor leptomeningeal collateral flow in multivariable logistic regression analyses (Table 3). These analyses show that higher admission glucose levels (OR 1.1 per mmol/L increase $(95 \%$ CI 1.0-1.2)), presence of a proximal MCA occlusion (OR 1.9 (95\% CI 1.3-3.0)), and an incomplete posterior circle of Willis (OR 1.7 (95 \% CI 1.1-2.6)) were independently related to poor leptomeningeal collateral flow.

\section{Determinants of leptomeningeal collateral flow: effect on the relation with clinical outcome}

Poor clinical outcome was more frequent in patients with poor leptomeningeal collateral flow (103/142 patients, $73 \%)$ than in patients with good leptomeningeal collateral flow (148/342 patients, $43 \%$ ). The corresponding unadjusted RR for the relation between poor leptomeningeal collateral flow and poor clinical outcome was 1.7 (95\% CI 1.4-2.0). In multivariable analyses this relation was not affected by the determinants of poor leptomeningeal collateral flow: admission glucose level, presence of a proximal MCA occlusion, and circle of Willis completeness (Table 4). Also, after additionally adjusting for other confounders (stroke severity and treatment), the relation between poor leptomeningeal collateral flow and poor clinical outcome was not affected. Furthermore, there was no interaction of admission glucose level, presence of a proximal MCA occlusion, and circle of Willis completeness with the patency of leptomeningeal collaterals for their relation with clinical outcome (all interaction term $p$ values $>0.05$ ).

\section{Discussion}

Our study shows that higher admission glucose level, the presence of an occlusion of the proximal MCA, and the presence of an incomplete posterior circle of Willis were determinants of poor leptomeningeal collateral flow in acute stroke patients. Poor leptomeningeal collateral flow was related to worse clinical outcome, but this relation was not influenced by admission glucose level, by the presence of a proximal MCA occlusion, or by the completeness of the circle of Willis.

Different factors may determine the patency of leptomeningeal collaterals in patients with an acute ischemic stroke. In mice, differences in genetic background are related to the extent of leptomeningeal collateral flow [21], and this could also play a role in humans, possibly due to innate interindividual differences in the cerebral arterial vascular tree. Furthermore, we showed that an incomplete posterior circle of Willis ipsilateral to the occlusion, in combination with a complete anterior circle of Willis, was related to poor leptomeningeal collateral flow. This finding may be explained partly by the lack of leptomeningeal collaterals between the posterior cerebral artery and MCA territories in patients with a fetal type posterior circle of Willis [2]. Furthermore, patency 
Table 1 Patient characteristics $(n=484)$

\begin{tabular}{|c|c|}
\hline Age (years) & $66.6(14.6)$ \\
\hline Male gender & $268(55.4)$ \\
\hline Stroke severity (NIHSS) & $13(8-17)$ \\
\hline Time from symptom onset to scan (minutes) & $100(64-159$ \\
\hline $\begin{array}{l}\text { Treatment (IV-rtPA, IAT, or mechanical } \\
\text { thrombectomy) }\end{array}$ & $361(74.6)$ \\
\hline Smoking & $144(29.8)$ \\
\hline Glucose $(\mathrm{mmol} / \mathrm{L})$ & $6.7(5.9-7.8)$ \\
\hline Systolic blood pressure (mmHg) & $151(26.5)$ \\
\hline Diastolic blood pressure (mmHg) & $84(17.2)$ \\
\hline \multicolumn{2}{|l|}{ Medical history } \\
\hline $\begin{array}{l}\text { Ischemic stroke or transient ischemic } \\
\text { attack }\end{array}$ & $87(18.0)$ \\
\hline Hypertension & $249(51.4)$ \\
\hline Diabetes & $61(12.6)$ \\
\hline Hyperlipidemia & $137(28.3)$ \\
\hline Atrial fibrillation & $79(16.3)$ \\
\hline \multicolumn{2}{|l|}{ CT angiography findings } \\
\hline Poor leptomeningeal collateral flow & $142(29.3)$ \\
\hline \multicolumn{2}{|l|}{ Location of intracranial occlusion } \\
\hline $\begin{array}{l}\text { Intracranial internal carotid artery } \\
\text { (and M1 segment) }\end{array}$ & $67(13.8)$ \\
\hline $\begin{array}{l}\text { M1 segment (without intracranial } \\
\text { internal carotid artery) }\end{array}$ & $234(48.3)$ \\
\hline M2 segment & $183(37.8)$ \\
\hline \multicolumn{2}{|l|}{ Circle of Willis } \\
\hline $\begin{array}{l}\text { Complete anterior and ipsilateral } \\
\text { posterior CoW }\end{array}$ & $152(31.4)$ \\
\hline $\begin{array}{l}\text { Incomplete ipsilateral posterior } \\
\text { CoW, complete anterior CoW }\end{array}$ & $296(61.2)$ \\
\hline $\begin{array}{l}\text { Incomplete anterior CoW, } \\
\text { complete ipsilateral posterior CoW }\end{array}$ & $8(1.7)$ \\
\hline $\begin{array}{l}\text { Incomplete anterior and ipsilateral } \\
\text { posterior CoW }\end{array}$ & $28(5.8)$ \\
\hline $\begin{array}{l}\text { Significant ipsilateral extracranial }>70 \% \\
\text { internal carotid artery stenosis or occlusion }\end{array}$ & $133(27.5)$ \\
\hline
\end{tabular}

All data are displayed as mean (standard deviation), median (interquartile range), or $n(\%)$

NIHSS National Institutes of Health Stroke Scale, IV-rtPA intravenous thrombolysis with recombinant tissue type plasminogen activator, IAT intra-arterial thrombolysis, $\mathrm{CoW}$ circle of Willis

of circle of Willis collaterals might be an expression of the potential to recruit collateral systems, possibly due to the same underlying genetic mechanisms as for the development of leptomeningeal collaterals [21]. Other circle of Willis variants that were investigated were not related to leptomeningeal collateral flow, although the numbers of patients with the combination of an incomplete anterior circle of Willis and a complete posterior circle of Willis $(n=8)$ and patients with an incomplete anterior and incomplete posterior circle of Willis $(n=28)$ are too low for firm conclusions.

Other acquired factors that potentially could determine the patency of leptomeningeal collaterals include vascular risk factors and the presence of a significant stenosis or occlusion of the internal carotid artery. The latter may also affect the size of the circle of Willis collaterals. Previous studies about associations of vascular risk factors with leptomeningeal collaterals were inconclusive. These studies suffered from problems such as small sample sizes [23, 24], retrospective study designs [23, 24], or rather simple comparative analyses instead of dedicated (regression) analyses to assess the relation with leptomeningeal collaterals [12, 22, 23]. In our large prospective study, we did not find a relation between age, hypertension, diabetes, and hyperlipidemia and poor leptomeningeal collateral flow. Neither did we find a relation between the presence of a $>70 \%$ stenosis or occlusion of the internal carotid artery and the patency of leptomeningeal collaterals. Therefore, our results suggest that exposure to vascular risk factors for atherosclerosis is not a major contributor to the recruitment of leptomeningeal collaterals in acute ischemic stroke. This is in contrast to the collaterals that are recruited in response to chronic hypoxemia in peripheral artery disease [37]. However, further studies including other vascular risk factors (e.g., diet, weight, physical activity, cholesterol) and other signs/markers of existing atherosclerosis should be performed to further clarify the relation between cardiovascular risk factors and leptomeningeal collateral flow.

Acute factors that are present at the time of stroke and that may determine the patency of leptomeningeal collaterals include admission systolic blood pressure, admission glucose level, and the location of the occlusion. Higher systolic blood pressure at admission was not related to poor leptomeningeal collateral flow in our study. One other study has shown that patients with increased leptomeningeal collateral flow have a lower systolic blood pressure than patients with normal or decreased leptomeningeal collateral flow [12], but no other study has confirmed this. Admission hyperglycemia has been related previously to both poor clinical outcome after ischemic stroke [38] and to poor leptomeningeal collateral flow [22]. Our results also show a relation between a higher admission glucose level and poor leptomeningeal collateral flow, but it remains unclear whether this is a true causal relation. Animal studies have demonstrated that acute hyperglycemia could lead to endothelial dysfunction and result in impaired collateral function [39]. Stress hyperglycemia in patients with acute ischemic stroke has been associated with poor leptomeningeal collateral flow [22]. Furthermore, acute hyperglycemia can reflect a pre-existing but unrecognized diabetes. Data on $\mathrm{HbA1c}$, indicating long-term elevated glucose levels, may be used to differentiate between stress hyperglycemia and diabetes [38], but could not be analyzed as this was missing in $36 \%$ of the patients in our study. However, as we did not find a relation between prior diabetes and poor leptomeningeal collateral flow, the effect of stress hyperglycemia probably dominates the effect of pre-existing diabetes.

The observation that patients with a proximal MCA occlusion often have poor leptomeningeal collateral flow has been shown 
Table 2 Univariable analyses for the association of patient characteristics and imaging findings with leptomeningeal collateral flow $(n=484)$

\begin{tabular}{|c|c|c|c|c|}
\hline & \multicolumn{2}{|c|}{ Leptomeningeal collateral flow } & \multirow[b]{2}{*}{ Odds ratio } & \multirow[b]{2}{*}{$\begin{array}{l}95 \% \text { confidence } \\
\text { interval }\end{array}$} \\
\hline & Good $(n=342)$ & Poor $(n=142)$ & & \\
\hline \multicolumn{5}{|l|}{ Patient characteristics } \\
\hline Age (years, odds ratio per decade) & $66.2(14.6)$ & $67.5(14.6)$ & 1.06 & $0.93-1.21$ \\
\hline $\begin{array}{l}\text { Systolic blood pressure }(\mathrm{mmHg} \text {, odds } \\
\text { ratio per } 10 \mathrm{mmHg})\end{array}$ & $152(26.4)$ & $150(27.0)$ & 0.97 & $0.90-1.04$ \\
\hline Glucose $(\mathrm{mmol} / \mathrm{L}$, odds ratio per $\mathrm{mmol} / \mathrm{L})$ & $6.6(5.8-7.7)$ & $6.7(6.2-8.4)$ & 1.10 & $1.01-1.20$ \\
\hline Hypertension & $174(50.9)$ & $75(52.8)$ & 1.08 & $0.73-1.60$ \\
\hline Diabetes & $43(12.6)$ & $18(12.7)$ & 1.01 & $0.56-1.82$ \\
\hline Hyperlipidemia & $99(28.9)$ & $38(26.8)$ & 0.90 & $0.58-1.39$ \\
\hline \multicolumn{5}{|l|}{ CT angiography findings } \\
\hline Proximal MCA occlusion $^{a}$ & $198(57.9)$ & $103(72.5)$ & 1.92 & $1.25-2.94$ \\
\hline \multicolumn{5}{|l|}{ Circle of Willis } \\
\hline $\begin{array}{l}\text { Complete anterior and ipsilateral } \\
\text { posterior CoW }\end{array}$ & $116(33.9)$ & $36(25.4)$ & Reference & Reference \\
\hline $\begin{array}{l}\text { Incomplete ipsilateral posterior CoW, } \\
\text { complete anterior CoW }\end{array}$ & $197(57.6)$ & $99(69.7)$ & 1.62 & $1.04-2.53$ \\
\hline $\begin{array}{l}\text { Incomplete anterior CoW, complete } \\
\text { ipsilateral posterior CoW }\end{array}$ & $7(2.0)$ & $1(0.7)$ & 0.46 & $0.05-3.87$ \\
\hline $\begin{array}{l}\text { Incomplete anterior and ipsilateral } \\
\text { posterior CoW }\end{array}$ & $22(6.4)$ & $6(4.2)$ & 0.88 & $0.33-2.33$ \\
\hline $\begin{array}{l}\text { Significant ipsilateral extracranial }>70 \% \\
\text { internal carotid artery stenosis or occlusion }\end{array}$ & $93(27.2)$ & $40(28.2)$ & 1.05 & $0.68-1.62$ \\
\hline
\end{tabular}

Data are displayed as mean (standard deviation), median (interquartile range), or $n(\%)$

MCA middle cerebral artery, $C o W$ circle of Willis

${ }^{\text {a }}$ Defined as an occlusion of the M1 segment with or without an occlusion of the intracranial internal carotid artery in recent studies $[4,12,40]$. In our study, the proportion of patients with poor leptomeningeal collateral flow was $61 \%$ higher if there was an occlusion of the M1 segment, instead of a more distal occlusion. There may be several explanations for this finding. First, small ischemic areas in patients with a distal occlusion are surrounded on all sides by adequately perfused brain tissue, including areas supplied by non-occluded M2 branches, allowing for better leptomeningeal collateral flow. On the other hand, patients with a proximal MCA occlusion have larger ischemic areas, less surrounding adequately perfused brain tissue, and hence there are less opportunities for sufficient leptomeningeal collateral flow. Another explanation could be that contrast filling of distal branches via leptomeningeal collaterals has not yet occurred in patients with a proximal MCA occlusion at the time the CTA is performed, as the time needed for contrast arrival via leptomeningeal collaterals might be longer for patients with an M1 occlusion than for patients with a more distal occlusion. This means that our study could have overestimated the number of patients with a proximal occlusion that have poor leptomeningeal collateral flow.

CTA is often used in clinical practice to image the cerebral vasculature in acute ischemic stroke and is increasingly
Table 3 Multivariable analyses for the association of patient characteristics and imaging findings with poor leptomeningeal collateral flow $(n=484)$

\begin{tabular}{lll}
\hline & Odds ratio & 95\% confidence interval \\
\hline Glucose (per mmol/L) & 1.10 & $1.01-1.20$ \\
Proximal MCA occlusion ${ }^{\mathrm{a}}$ & 1.94 & $1.26-2.99$ \\
Circle of Willis & & \\
$\quad$ Complete anterior and ipsilateral posterior CoW & Reference & Reference \\
Incomplete ipsilateral posterior CoW, complete anterior CoW & 1.66 & $1.06-2.61$ \\
Incomplete anterior CoW, complete ipsilateral posterior CoW & 0.37 & $0.04-3.15$ \\
Incomplete anterior and ipsilateral posterior CoW & 1.02 & $0.37-2.76$ \\
\hline$M C A$ middle cerebral artery, CoW circle of Willis & & \\
${ }^{a}$ Defined as an occlusion of the M1 segment with or without an occlusion of the intracranial internal carotid artery
\end{tabular}


Table 4 Relative risks for the relation between poor leptomeningeal collateral flow and poor clinical outcome $(n=484)$

\begin{tabular}{|c|c|c|}
\hline & Relative risk & $\begin{array}{l}95 \% \text { confidence } \\
\text { interval }\end{array}$ \\
\hline Unadjusted & 1.68 & $1.43-1.96$ \\
\hline \multicolumn{3}{|l|}{ Adjusted for } \\
\hline Glucose & 1.63 & $1.39-1.91$ \\
\hline Proximal MCA occlusion $^{\mathrm{a}}$ & 1.54 & $1.32-1.80$ \\
\hline $\begin{array}{l}\text { Additionally adjusted for } \\
\text { stroke severity (NIHSS) }\end{array}$ & 1.31 & $1.12-1.53$ \\
\hline $\begin{array}{l}\text { Additionally adjusted for } \\
\text { treatment (IV-rtPA, IAT, or } \\
\text { mechanical thrombectomy) }\end{array}$ & 1.55 & $1.33-1.80$ \\
\hline Circle of Willis completeness & 1.66 & $1.41-1.94$ \\
\hline
\end{tabular}

MCA middle cerebral artery, NIHSS National Institutes of Health Stroke Scale, IV-rtPA intravenous thrombolysis with recombinant tissue type plasminogen activator, IAT intra-arterial thrombolysis

${ }^{\mathrm{a}}$ Defined as an occlusion of the M1 segment with or without an occlusion of the intracranial internal carotid artery

important to select patients for endovascular treatment. As such, it is important to investigate leptomeningeal collateral flow as seen on CTA. Newer techniques such as CTA reconstruction from CTP data and multiphase CTA make the CTA independent from timing of contrast administration and scan acquisition and could improve assessment of the collateral circulation [41, 42]. However, these techniques are currently not widely available for use in clinical practice. Furthermore, the thin slice CTP data that is needed for high-quality reconstruction of CTA from CTP was missing in a substantial part of our cohort. We felt that it was more important to have a large sample size with enough power for our analyses than to compromise on this when using newer CTA from CTP techniques. The above considerations made us decide to use standard CTA instead of newer CTA techniques. Regarding the location of the occlusion, we classified all occlusions to the most proximal part of the occlusion. A limitation is that this does not take the length of the thrombus into account. Furthermore, we used a dichotomized classification of leptomeningeal collateral flow in our analyses. Although previous studies also used this approach $[8,18,43]$, this may oversimplify the complex pathophysiology of stroke hemodynamics. Nonetheless, through the use of a dichotomized score, the analyses could be performed with logistic regression, making the results better understandable and interpretable for many physicians.

\section{Conclusions}

Our study shows that admission glucose level, a proximal MCA occlusion, and an incomplete ipsilateral posterior circle of Willis are determinants of leptomeningeal collateral flow that represent a combination of congenital, acquired, and acute factors. After adjustment for these determinants, leptomeningeal collateral flow remains related to clinical outcome.

Acknowledgements The Dutch acute stroke study (DUST) investigators are:

Academic Medical Center, Amsterdam, The Netherlands (CBLM Majoie, YBWEM Roos); Catharina Hospital, Eindhoven, The Netherlands (LEM Duijm, K Keizer); Erasmus University Medical Center, Rotterdam, The Netherlands (A van der Lugt, DWJ Dippel); Gelre Hospitals, Apeldoorn, The Netherlands (KE Droogh-de Greve, HP Bienfait); Leiden University Medical Center, Leiden, The Netherlands (MAA van Walderveen, MJH Wermer); Medical Center Haaglanden, The Hague, The Netherlands (GJ Lycklama à Nijeholt, J Boiten); Onze Lieve Vrouwe Gasthuis, Amsterdam, The Netherlands (DA Duyndam, VIH Kwa); Radboud University Medical Center, Nijmegen, The Netherlands (FJA Meijer, EJ van Dijk); Rijnstate Hospital, Arnhem, The Netherlands (FOHW Kesselring, J Hofmeijer); St. Antonius Hospital, Nieuwegein, The Netherlands (JA Vos, WJ Schonewille); St. Elisabeth Hospital, Tilburg, The Netherlands (WJ van Rooij, PLM de Kort); St. Franciscus Hospital, Rotterdam, The Netherlands (CC Pleiter, SLM Bakker); VU University Medical Center, Amsterdam, The Netherlands (JCJ Bot, MC Visser); and University Medical Center Utrecht, Utrecht, The Netherlands (BK Velthuis, IC van der Schaaf, JW Dankbaar, WPTM Mali, T van Seeters, AD Horsch, JM Niesten, GJ Biessels, LJ Kappelle, MJA Luitse, Y van der Graaf). This study was supported by the Dutch Heart Foundation (2008T034) and the NutsOhra Foundation (0903-012).

Compliance with ethical standards We declare that all human studies have been approved by the medical ethics committee of the University Medical Center Utrecht, The Netherlands, and have therefore been performed in accordance with the ethical standards laid down in the 1964 Declaration of Helsinki and its later amendments. We declare that all participants gave informed consent prior to inclusion in this study; however, the medical ethics committee waived informed consent for patients who died before informed consent could be obtained.

Conflict of interest We declare that we have no conflict of interest.

Open Access This article is distributed under the terms of the Creative Commons Attribution 4.0 International License (http:// creativecommons.org/licenses/by/4.0/), which permits unrestricted use, distribution, and reproduction in any medium, provided you give appropriate credit to the original author(s) and the source, provide a link to the Creative Commons license, and indicate if changes were made.

\section{References}

1. Liebeskind DS (2003) Collateral circulation. Stroke 34:2279-2284

2. van Raamt AF, Mali WP, van Laar PJ, van der Graaf Y (2006) The fetal variant of the circle of Willis and its influence on the cerebral collateral circulation. Cerebrovasc Dis 22:217-224

3. Kim JJ, Fischbein NJ, Lu Y, Pham D, Dillon WP (2004) Regional angiographic grading system for collateral flow: correlation with cerebral infarction in patients with middle cerebral artery occlusion. Stroke 35:1340-1344

4. Tan IY, Demchuk AM, Hopyan J, Zhang L, Gladstone D, Wong K, Martin M, Symons SP, Fox AJ, Aviv RI (2009) CT angiography 
clot burden score and collateral score: correlation with clinical and radiologic outcomes in acute middle cerebral artery infarct. AJNR Am J Neuroradiol 30:525-531

5. Miteff F, Levi CR, Bateman GA, Spratt N, McElduff P, Parsons MW (2009) The independent predictive utility of computed tomography angiographic collateral status in acute ischaemic stroke. Brain 132:2231-2238

6. Maas MB, Lev MH, Ay H, Singhal AB, Greer DM, Smith WS, Harris GJ, Halpern E, Kemmling A, Koroshetz WJ, Furie KL (2009) Collateral vessels on CT angiography predict outcome in acute ischemic stroke. Stroke 40:3001-3005

7. Angermaier A, Langner S, Kirsch M, Kessler C, Hosten N, Khaw AV (2011) CT-angiographic collateralization predicts final infarct volume after intra-arterial thrombolysis for acute anterior circulation ischemic stroke. Cerebrovasc Dis 31:177-184

8. Aoki J, Tateishi Y, Cummings CL, Cheng-Ching E, Ruggieri P, Hussain MS, Uchino K (2014) Collateral flow and brain changes on computed tomography angiography predict infarct volume on early diffusion-weighted imaging. J Stroke Cerebrovasc Dis 23: 2845-2850

9. Bang OY, Saver JL, Buck BH, Alger JR, Starkman S, Ovbiagele B, Kim D, Jahan R, Duckwiler GR, Yoon SR, Vinuela F, Liebeskind DS (2008) Impact of collateral flow on tissue fate in acute ischaemic stroke. J Neurol Neurosurg Psychiatry 79:625-629

10. Christoforidis GA, Mohammad Y, Kehagias D, Avutu B, Slivka AP (2005) Angiographic assessment of pial collaterals as a prognostic indicator following intra-arterial thrombolysis for acute ischemic stroke. AJNR Am J Neuroradiol 26:1789-1797

11. Kucinski T, Koch C, Eckert B, Becker V, Kromer H, Heesen C, Grzyska U, Freitag HJ, Rother J, Zeumer H (2003) Collateral circulation is an independent radiological predictor of outcome after thrombolysis in acute ischaemic stroke. Neuroradiology 45:11-18

12. Lima FO, Furie KL, Silva GS, Lev MH, Camargo EC, Singhal AB, Harris GJ, Halpern EF, Koroshetz WJ, Smith WS, Yoo AJ, Nogueira RG (2010) The pattern of leptomeningeal collaterals on $\mathrm{CT}$ angiography is a strong predictor of long-term functional outcome in stroke patients with large vessel intracranial occlusion. Stroke 41:2316-2322

13. Menon BK, Smith EE, Modi J, Patel SK, Bhatia R, Watson TW, Hill MD, Demchuk AM, Goyal M (2011) Regional leptomeningeal score on CT angiography predicts clinical and imaging outcomes in patients with acute anterior circulation occlusions. AJNR Am J Neuroradiol 32:1640-1645

14. Souza LC, Yoo AJ, Chaudhry ZA, Payabvash S, Kemmling A, Schaefer PW, Hirsch JA, Furie KL, Gonzalez RG, Nogueira RG, Lev MH (2012) Malignant CTA collateral profile is highly specific for large admission DWI infarct core and poor outcome in acute stroke. AJNR Am J Neuroradiol 33:1331-1336

15. Seeta Ramaiah S, Churilov L, Mitchell P, Dowling R, Yan B (2014) The impact of arterial collateralization on outcome after intraarterial therapy for acute ischemic stroke. AJNR Am J Neuroradiol 35:667-672

16. Nambiar V, Sohn SI, Almekhlafi MA, Chang HW, Mishra S, Qazi E, Eesa M, Demchuk AM, Goyal M, Hill MD, Menon BK (2014) CTA collateral status and response to recanalization in patients with acute ischemic stroke. AJNR Am J Neuroradiol 35:884-890

17. Brunner F, Tomandl B, Hanken K, Hildebrandt H, Kastrup A (2014) Impact of collateral circulation on early outcome and risk of hemorrhagic complications after systemic thrombolysis. Int $\mathbf{J}$ Stroke 9:992-998

18. Schramm P, Schellinger PD, Fiebach JB, Heiland S, Jansen O, Knauth M, Hacke W, Sartor K (2002) Comparison of CT and CT angiography source images with diffusion-weighted imaging in patients with acute stroke within 6 hours after onset. Stroke 33:2426-2432

19. van Seeters T, Biessels GJ, Kappelle LJ, van der Schaaf IC, Dankbaar JW, Horsch AD, Niesten JM, Luitse MJ, Majoie CB,
Vos JA, Schonewille WJ, van Walderveen MA, Wermer MJ, Duijm LE, Keizer K, Bot JC, Visser MC, van der Lugt A, Dippel DW, Kesselring FO, Hofmeijer J, Lycklama à Nijeholt GJ, Boiten J, van Rooij WJ, de Kort PL, Roos YB, van Dijk EJ, Pleiter CC, Mali WP, van der Graaf Y, Velthuis BK (2015) The prognostic value of $\mathrm{CT}$ angiography and CT perfusion in acute ischemic stroke. Cerebrovasc Dis 40:258-269

20. van Seeters T, Biessels GJ, Kappelle LJ, van der Schaaf IC, Dankbaar JW, Horsch AD, Niesten JM, Luitse MJ, Majoie CB, Vos JA, Schonewille WJ, van Walderveen MA, Wermer MJ, Duijm LE, Keizer K, Bot JC, Visser MC, van der Lugt A, Dippel DW, Kesselring FO, Hofmeijer J, Lycklama à Nijeholt GJ, Boiten J, van Rooij WJ, de Kort PL, Roos YB, Meijer FJ, Pleiter CC, Mali WP, van der Graaf Y, Velthuis BK (2016) CT angiography and CT perfusion improve prediction of infarct volume in patients with anterior circulation stroke. Neuroradiology 58:327-337

21. Zhang H, Prabhakar P, Sealock R, Faber JE (2010) Wide genetic variation in the native pial collateral circulation is a major determinant of variation in severity of stroke. J Cereb Blood Flow Metab 30:923-934

22. Menon BK, Smith EE, Coutts SB, Welsh DG, Faber JE, Goyal M, Hill MD, Demchuk AM, Damani Z, Cho KH, Chang HW, Hong JH, Sohn SI (2013) Leptomeningeal collaterals are associated with modifiable metabolic risk factors. Ann Neurol 74:241-248

23. Arsava EM, Vural A, Akpinar E, Gocmen R, Akcalar S, Oguz KK, Topcuoglu MA (2014) The detrimental effect of aging on leptomeningeal collaterals in ischemic stroke. J Stroke Cerebrovasc Dis 23:421-426

24. Malik N, Hou Q, Vagal A, Patrie J, Xin W, Michel P, Eskandari A, Jovin T, Wintermark M (2014) Demographic and clinical predictors of leptomeningeal collaterals in stroke patients. J Stroke Cerebrovasc Dis 23:2018-2022

25. Berkhemer OA, Fransen PS, Beumer D, van den Berg LA, Lingsma HF, Yoo AJ, Schonewille WJ, Vos JA, Nederkoorn PJ, Wermer MJ, van Walderveen MA, Staals J, Hofmeijer J, van Oostayen JA, Nijeholt GJ L à, Boiten J, Brouwer PA, Emmer BJ, de Bruijn SF, van Dijk LC, Kappelle LJ, Lo RH, van Dijk EJ, de Vries J, de Kort PL, van Rooij WJ, van den Berg JS, van Hasselt BA, Aerden LA, Dallinga RJ, Visser MC, Bot JC, Vroomen PC, Eshghi O, Schreuder TH, Heijboer RJ, Keizer K, Tielbeek AV, den Hertog HM, Gerrits DG, van den Berg-Vos RM, Karas GB, Steyerberg EW, Flach HZ, Marquering HA, Sprengers ME, Jenniskens SF, Beenen LF, van den Berg R, Koudstaal PJ, van Zwam WH, Roos YB, van der Lugt A, van Oostenbrugge RJ, Majoie CB, Dippel DW (2015) A randomized trial of intraarterial treatment for acute ischemic stroke. N Engl J Med 372:11-20

26. Campbell BC, Mitchell PJ, Kleinig TJ, Dewey HM, Churilov L, Yassi N, Yan B, Dowling RJ, Parsons MW, Oxley TJ, Wu TY, Brooks M, Simpson MA, Miteff F, Levi CR, Krause M, Harrington TJ, Faulder KC, Steinfort BS, Priglinger M, Ang T, Scroop R, Barber PA, McGuinness B, Wijeratne T, Phan TG, Chong W, Chandra RV, Bladin CF, Badve M, Rice H, de Villiers L, Ma H, Desmond PM, Donnan GA, Davis SM (2015) Endovascular therapy for ischemic stroke with perfusion-imaging selection. N Engl J Med 372:1009-1018

27. Goyal M, Demchuk AM, Menon BK, Eesa M, Rempel JL, Thornton J, Roy D, Jovin TG, Willinsky RA, Sapkota BL, Dowlatshahi D, Frei DF, Kamal NR, Montanera WJ, Poppe AY, Ryckborst KJ, Silver FL, Shuaib A, Tampieri D, Williams D, Bang OY, Baxter BW, Burns PA, Choe H, Heo JH, Holmstedt CA, Jankowitz B, Kelly M, Linares G, Mandzia JL, Shankar J, Sohn SI, Swartz RH, Barber PA, Coutts SB, Smith EE, Morrish WF, Weill A, Subramaniam S, Mitha AP, Wong JH, Lowerison MW, Sajobi TT, Hill MD (2015) Randomized assessment of rapid endovascular treatment of ischemic stroke. N Engl J Med 372: 1019-1030 
28. Saver JL, Goyal M, Bonafe A, Diener HC, Levy EI, Pereira VM, Albers GW, Cognard C, Cohen DJ, Hacke W, Jansen O, Jovin TG, Mattle HP, Nogueira RG, Siddiqui AH, Yavagal DR, Baxter BW, Devlin TG, Lopes DK, Reddy VK, du Mesnil de Rochemont R, Singer OC, Jahan R (2015) Stent-retriever thrombectomy after intravenous t-PA vs. t-PA alone in stroke. N Engl J Med 372:2285-2295

29. Jovin TG, Chamorro A, Cobo E, de Miquel MA, Molina CA, Rovira A, San Roman L, Serena J, Abilleira S, Ribo M, Millan M, Urra X, Cardona P, Lopez-Cancio E, Tomasello A, Castano C, Blasco J, Aja L, Dorado L, Quesada H, Rubiera M, HernandezPerez M, Goyal M, Demchuk AM, von Kummer R, Gallofre M, Davalos A (2015) Thrombectomy within 8 hours after symptom onset in ischemic stroke. N Engl J Med 372:2296-2306

30. Puetz V, Dzialowski I, Hill MD, Subramaniam S, Sylaja PN, Krol A, O’Reilly C, Hudon ME, Hu WY, Coutts SB, Barber PA, Watson T, Roy J, Demchuk AM (2008) Intracranial thrombus extent predicts clinical outcome, final infarct size and hemorrhagic transformation in ischemic stroke: the clot burden score. Int J Stroke 3:230 236

31. van Seeters T, Biessels GJ, van der Schaaf IC, Dankbaar JW, Horsch AD, Luitse MJ, Niesten JM, Mali WP, Kappelle LJ, van der Graaf Y, Velthuis BK (2014) Prediction of outcome in patients with suspected acute ischaemic stroke with CT perfusion and CT angiography: the Dutch acute stroke trial (DUST) study protocol. BMC Neurol 14:37

32. Rothwell PM, Eliasziw M, Gutnikov SA, Fox AJ, Taylor DW, Mayberg MR, Warlow CP, Barnett HJ (2003) Analysis of pooled data from the randomised controlled trials of endarterectomy for symptomatic carotid stenosis. Lancet 361:107-116

33. van Swieten JC, Koudstaal PJ, Visser MC, Schouten HJ, van Gijn J (1988) Interobserver agreement for the assessment of handicap in stroke patients. Stroke 19:604-607

34. Janssen PM, Visser NA, Dorhout Mees SM, Klijn CJ, Algra A, Rinkel GJ (2010) Comparison of telephone and face-to-face assessment of the modified Rankin Scale. Cerebrovasc Dis 29:137-139

35. Steyerberg EW (2009) Clinical prediction models: a practical approach to development, validation, and updating. Springer, New York

36. UCLA: Statistical Consulting Group R data analysis examples: Poisson regression. Available via http://www.ats.ucla.edu/stat/r/dae/poissonreg. $\mathrm{htm}$. Accessed July 72015

37. Hamburg NM, Balady GJ (2011) Exercise rehabilitation in peripheral artery disease: functional impact and mechanisms of benefits. Circulation 123:87-97

38. Luitse MJ, Biessels GJ, Rutten GE, Kappelle LJ (2012) Diabetes, hyperglycaemia, and acute ischaemic stroke. Lancet Neurol 11: 261-271

39. Tsuruta R, Fujita M, Ono T, Koda Y, Koga Y, Yamamoto T, Nanba M, Shitara M, Kasaoka S, Maruyama I, Yuasa M, Maekawa T (2010) Hyperglycemia enhances excessive superoxide anion radical generation, oxidative stress, early inflammation, and endothelial injury in forebrain ischemia/reperfusion rats. Brain Res 1309:155163

40. Saarinen JT, Rusanen H, Sillanpaa N (2014) Collateral score complements clot location in predicting the outcome of intravenous thrombolysis. AJNR Am J Neuroradiol 35:1892-1896

41. Smit EJ, Vonken EJ, van Seeters T, Dankbaar JW, van der Schaaf IC, Kappelle LJ, van Ginneken B, Velthuis BK, Prokop M (2013) Timing-invariant imaging of collateral vessels in acute ischemic stroke. Stroke 44:2194-2199

42. Menon BK, d'Esterre CD, Qazi EM, Almekhlafi M, Hahn L, Demchuk AM, Goyal M (2015) Multiphase CT angiography: a new tool for the imaging triage of patients with acute ischemic stroke. Radiology 275:510-520

43. Tan JC, Dillon WP, Liu S, Adler F, Smith WS, Wintermark M (2007) Systematic comparison of perfusion-CT and CTangiography in acute stroke patients. Ann Neurol 61:533-543 